\title{
Cultura y universidad ${ }^{\mathrm{A}}$
}

\section{Germán Colmenares}

\section{La "demanda" de las humanidades}

Los sobresaltos financieros de la Universidad [del Valle], que responden a una crisis más generalizada de la institución en Colombia, han llamado la atención sobre las condiciones gravosas que imponen las facultades de ciencias humanas (o ciencias sociales) y de humanidades. Los índices "estudiantes por profesor" o "estudiantes por programa" alarman a quienes se ocupan de trazar políticas universitarias, pues tales índices revelarían un costo demasiado elevado que se aplica a una producción de muy dudosa colocación en un mercado de trabajo. Un "Boletín Estadístico" - elaborado por la Oficina de Planeación de la Universidad del Valle - dice escuetamente, al referirse a la población estudiantil matriculada en el año académico 1971-1972: “A la División de Humanidades correspondió el más bajo porcentaje de la población. Apenas el 2.93\%, con lo cual se manifiesta la baja demanda que tienen sus planes de estudio" (subrayado en el original). En enero de 1971 la misma oficina comprobaba que el $68.2 \%$ de los egresados de humanidades se dedicaba a actividades docentes, con énfasis en los niveles secundario y universitario, mientras que el $14.7 \%$ no realizaba actividad alguna. Una situación semejante se observa con respecto a los egresados de la Facultad de Ciencias. El proyecto de "Mejoramiento de la enseñanza e investigación en las Ciencias Básicas" señala que, "sea porque no tienen otra que

A Estravagario - Revista cultural del periódico El Pueblo, de Cali-, n. ${ }^{\circ}$ 22, junio de 1975, 1-6. Germán Colmenares escribió varias veces sobre la universidad pública en los años setenta. Comentó sus repetidos cierres, sus carencias presupuestales, el constante ascenso de la violencia ejercida por grupos radicales de estudiantes, alimentada por muchos de sus dirigentes políticos de izquierda en la universidad, violencia con la que los movimientos estudiantiles se colocaban en la misma lógica de los gobiernos, y violencia continuada luego por las llamadas "fuerzas oscuras de la sociedad". Siguió con gran cuidado, como lo muestra en este texto, el ascenso de la "economía de la educación” y del saber de la administración universitaria, de orientación tecnocrática, como formas avanzadas de las nuevas ideologías impulsadas por el Estado para la dirección de la universidad, pero sabía, y lo dejó en claro, que la reivindicación del viejo humanismo opuesto a la ciencia ya no era ninguna alternativa para una nueva universidad, que más bien debería hacer de la reflexión crítica, basada en las ciencias sociales, uno de sus grandes apoyos y estímulos. En todos sus textos sobre el problema, como constante repetida, Colmenares insistió en la defensa de la autonomía universitaria, pero no en sentido territorial, tribal, sino como lugar de ejercicio del pensamiento autónomo de una comunidad de profesores y estudiantes que eran capaces de discutir sobre la institución y lograr acuerdos razonables sobre su marcha al servicio de la sociedad. Sobre Estravagario puede verse Estravagario. Selección de textos de María Mercedes Carranza. Presentación de Fernando Garavito (Bogotá: Instituto Colombiano de Cultura, 1976). Hemos sido informados que no hay archivos disponibles para consulta de esta importante experiencia periodística y de divulgación cultural, en donde Colmenares publicó muchas notas que glosaban o adelantaban sus propias investigaciones. 
hacer, sea porque el conocimiento tiende a comunicarse, muchos de estos científicos hacen docencia". Y nuestra Oficina de Planeación lo confirma: el 52.4\% de los científicos egresados de la Universidad del Valle hasta 1971 se dedicaba a enseñar y un $25 \%$ continuaba estudiando a niveles de especialización, con la perspectiva de dedicarse a la enseñanza.

Es interesante contrastar estos resultados con un plan decenal elaborado para la antigua Facultad de Filosofía, Letras e Historia de la Universidad del Valle en 1955, pues así puede advertirse que lo que se cuestiona no son los planes de estudio en sí mismos, su alcance o significación en el contexto social, sino simplemente la situación a que ha conducido una crisis universitaria.

Según el Plan decenal para 1966-1975, la población estudiantil de los planes de Filosofía, Letras e Historia debía proyectarse con un incremento moderado que alcanzara los 200 estudiantes en 1975-1976. Este resultado modesto parecía entonces - a la misma Oficina de Planeación que da ahora la voz de alarma - deseable y realista. La razón de esta tolerancia estriba en que entonces, con los estudios generales y los cursos de extensión, el crecimiento real de la población estudiantil que se esperaba que atendiera la facultad se daba en órdenes de miles: 1537 estudiantes en 1966-1967 y 4217 en 1974, es decir la totalidad de la población universitaria o poco menos.

Así, el crecimiento moderado de los planes de estudio propios podía ampararse en otras proyecciones que disimularan el hecho de que no se esperaba que tales planes tuvieran una demanda inaudita.

\section{2. “Cuestionamiento" y "adecuación"}

A partir de 1971, la crisis universitaria colombiana ha venido reflejando complejos desarrollos sociales, políticos y económicos que se haría necesario examinar a fondo si se pretendiera encarar problemas más inmediatos. En el decenio anterior nadie "cuestionaba" las facultades de Filosofía que podían formular sus objetivos (de manera que hoy nos parece harto vaga) con respecto a un contexto de cultura universal o con respecto a una formación humana "integral". Hoy se observa un repliegue de tales posiciones y aun los menos escépticos no se atreven a mencionar siquiera la "humanización" de las carreras técnicas o la necesidad de un supuesto equilibrio entre "técnica" y "humanismo" en el interior de la Universidad.

Hoy es evidente, de un lado, que la tecnología ya trae consigo elementos ideológicos con los que no puede competir un humanismo desueto. Este "humanismo", entendido como el dominio de los elementos de una tradición de tipo literario o como la capacidad de apreciación y goce estéticos que se adquiere mediante una formación muy peculiar (dominio de lenguas muertas, de teorías estéticas, etc.) no sirve para encarar las necesidades humanas más apremiantes. De otro lado, se ha advertido que este tipo de "humanismo" no pasa de ser un signo distintivo de una clase social, que 
opone obstinadamente la "necesidad" de perpetuar valores que le "pertenecen" y que justifican su existencia a las pretensiones de las "masas ignorantes e incultas".

Esta posición hunde sus raíces en nostalgias aristocratizantes - de comienzos del siglo XIX europeo - que comenzaban a comprobar la degradación impuesta por la civilización industrial. Su elemento positivo radica en una crítica implícita a esas condiciones de degradación y en su aspiración a recobrar una "humanidad" que, paradójicamente, se inscribe en estadios sociales remotos. Por eso no es raro que las clases dirigentes en Colombia mantengan una posición ambigua frente a lo que se denomina "la cultura". De un lado, la aceptan como ingrediente de "distinción" y de otro la repudian como fuente virtual de crítica al sistema. Esto lleva a minimizar los elementos críticos contenidos en el concepto cultural hasta reducirlo a un cascaron huero, en el que solo permanecen una retórica y un culto excesivo, meras manifestaciones formales. Por eso tampoco es raro ver a esa clase social en trance permanente de simular cultura.

Hasta aquí se ha disuelto un equívoco en la noción de "cultura", sobre el que se volverá más adelante. Baste observar por ahora que, a partir de 1971, el rechazo hacia las humanidades y hacia las ciencias humanas se ha venido concretando en una política, es decir en una opción concreta por desarrollos prioritarios en educación. ¿Cuál ha sido esta opción? De hecho, se ha renunciado abiertamente a cualquier pretensión de "humanizar" las carreras técnicas. Las aspiraciones de la pequeña burguesía en el sentido de obtener una rápida profesionalización, exenta de elementos ideológicos que contradicen en parte la ideología implícita en el desarrollo tecnológico, han sido atendidas más allá de cualquier previsión. Antes que cuestionar el contenido y la verdadera significación de las "humanidades", el procedimiento adoptado ha consistido más bien en liberar el "mercado universitario" de cualquier intervención y "dejar flotando" las humanidades al vaivén de una "oferta" (excesiva) y una "demanda" (escasa) que, naturalmente, las ha ido depreciando. Así, ninguna división [académica] parece interesada en este "mercado libre", en programar cursos que no respondan a una exigencia profesional muy concreta. Algunas se atreven todavía a intentarlo, por uno o dos semestres, para comprobar una vez más que futuros arquitectos, médicos o ingenieros no muestran una inclinación marcada por el goce de valores intelectuales o estéticos. En realidad esto se sabía desde su ingreso a la Universidad. De lo contrario hubieran ingresado a nuestra División de Humanidades.

El desvío de los estudiantes de otras carreras hacia las "humanidades" parece producir un efecto paralizante en los programas mismos de la División. La pretensión de formar filósofos, letrados o historiadores sólo tenía sentido - en el contexto del decenio anterior - como una preparación de un personal idóneo y creciente que atendiera las necesidades mismas de la Universidad en el ciclo de los estudios Generales. El proceso de autogeneración en este sentido ha sido parado en seco por la supresión del ciclo básico y por eso se tiene la impresión de que la función de las facultades de 
humanidades ha desaparecido. Una solución aparente parecería ser la de integrar el personal de estas facultades a las de educación, a las que se señala un porvenir más prometedor.

De esta descripción somera se desprende que, pese a una muy difundida retórica sobre las "humanidades" y la "cultura", su existencia depende de circunstancias que nada tienen que ver con la "autonomía de los valores educativos", sino con las de un mercado que, en nuestro caso, ha sido eliminado por conveniencias políticas.

Aquí, sin embargo, como en el caso de "la cultura", opera una falacia que consiste en identificar el mercado con las necesidades sociales. Se nos dice que la Universidad debe adecuar su producto a las condiciones de un mercado profesional. Para lograrlo se bloquean las finanzas de la institución obligándola a deshacerse de lo que se considera superfluo y cuya existencia obedecía a las necesidades de un "modelo" universitario en crisis. Es claro que los esfuerzos de la "política educativa" del Estado no se dirigen a incrementar el saber (que sencillamente se importa), sino en adaptar la universidad a las exigencias de un aparato productivo manejado por empresarios privados. La contratación de habilidades específicas por parte de estos o del Estado, que secunda sus esfuerzos, es lo que constituye el mercado profesional.

Ahora bien, las condiciones de este mercado son condiciones incontrolables por parte de los poderes públicos en un país subdesarrollado. La compra de bienes y servicios - tanto por parte del sector privado como del sector público - está supeditada a la iniciativa de monopolios o de organismos internacionales. Por eso en materia educativa (el sector encargado de organizar ciertos aspectos del mercado de trabajo) los "modelos" se suceden unos a otros, y cada cambio señala un fracaso del "modelo" anterior, recomendado también por "expertos" internacionales. La consigna de "modernizar" la educación ha sido asumida varias veces por el Estado colombiano en su afán de satisfacer ciertos patrones internacionales que se adaptan mal a estructuras agrarias de valores y de comportamiento. El ritmo de "modernización" general, es decir, de inversiones de capital extranjero, ha dejado atrás, muy atrás, esas estructuras que se requiere adecuar a marchas forzadas.

El fracaso de los "modelos" ha obedecido, en parte, al surgimiento de factores políticos imprevistos que el "modelo" subsiguiente tratará de neutralizar. Universidad profesional, campus departamentalizado, universidad a distancia, universidad sin estudiantes, son los pasos de esta experimentación. Uno de ellos ha consistido en el desmantelamiento sistemático de focos perturbadores o de una organización del saber que no se adapte al "modelo".

Así las cosas, la cuestión para la Universidad consiste en saber cuándo dejará de ser el sujeto de estas iniciativas. Cuando, en su interior, podrá encontrar directrices lo suficientemente sólidas como para repeler la agresión sistemática de apetitos políticos y burocráticos, deseosos de "experimentación". 
Este problema, sin embargo, depende de la capacidad crítica que se desarrolle en el seno de la Universidad. En cierta forma - ya que no es posible tener otra - de su autonomía intelectual.

\section{La "cultura" y el "mercado"}

Se había mencionado antes la existencia de dos falacias, relativas al sentido de la "cultura" y a la identificación del mercado con las necesidades sociales. Respecto de la "cultura", que se señala de manera general como el objeto de las "humanidades", se había dicho que era el patrimonio de una clase social, que se identificaba con sus "valores". Ahora bien, es muy notorio el hecho de que la clase dirigente colombiana ha cultivado siempre una afición desmedida por la retórica. La "actividad creadora" de los letrados colombianos se ha desarrollado preferentemente en el periodismo y en las plazas públicas. Esa orientación ha obedecido tanto a las necesidades de una función política como a la de mantener un fácil prestigio de los "letrados". Los contenidos mismos de esta tradición retórica no son notorios por su originalidad. Se trata, en la mayoría de los casos, de una recepción superficial de cánones de la cultura europea, a la que las clases dirigentes han rendido un culto ambiguo, teñido de complejos de inferioridad cultural.

Esta actitud se ha reflejado, en distintas etapas de la universidad [colombiana], en versiones del "humanismo" que van desde el énfasis gramatical hasta la propaganda abierta - durante los años de la Guerra Fría — de una "cultura Occidental cristiana. Estas versiones han actuado como una ideología paralizadora de los elementos críticos contenidos en un complejo cultural propio. Frente al producto acabado de la cultura europea, que se ofrecía como una fuente original de goce estético, era natural que una clase social desarraigada experimentara una admiración servil. Sus complejos de inferioridad — nacidos de una realidad nacional extraña a tales goces - la impulsaron siempre a desconocer el sentido real de lo que constituye la cultura.

Esta, dentro de su contexto mismo europeo, no es otra cosa que la expresión de un modo de vida y sus manifestaciones no se dan solamente en productos acabados en el plano literario o artístico. El concepto antropológico de cultura - que no es sino la aplicación a un terreno específico de esta concepción global— reconoce estas mismas manifestaciones en las llamadas "culturas primitivas". En Colombia, en donde la "cultura" solo se reconoce como una forma de suplantación de las peculiaridades nacionales, este sentido antropológico solo ha logrado penetrar como un elemento más del remedo europeizante o norteamericano. Así, el Estado mantiene institutos cuya actividad está dedicada a precarias investigaciones sobre esa realidad "extraña" y marginal que son las raíces mismas de nuestra formación social.

Se insiste, sin embargo, en que la universidad debe adecuarse a las necesidades de un mercado. El mercado — como se ha anotado un poco antes - quiere hacerse 
pasar como un reflejo de las necesidades sociales. Si un tipo de saber no tiene un mercado esto quiere decir, a los ojos de los organismos planificadores, que su necesidad social es nula. El razonamiento resulta muy curioso si se piensa en sus aplicaciones dentro de un complejo cultural que el Estado debería preservar.

Nadie esperaría que en un mercado condicionado por mecanismos de tipo capitalista esta labor de preservación, que es fundamentalmente crítica, tuviera una demanda similar a la de un saber pragmático. La recepción y adaptación de una tecnología, por ejemplo, que se juzga como un elemento indispensable para la "modernización" y el "desarrollo", representa el tipo acabado de actividad que se asigna hoy al "aparato educativo". Esta es una prioridad acordada por una decisión política del Estado y responde a las necesidades de empresarios industriales. Se trata de comprar patentes y avances tecnológicos en vista a acrecentar una tasa de ganancias y de ponerla a niveles aceptables tanto de la burguesía nacional como del capital internacional. El Estado, y su aparato educativo, se encargarán por su parte de difundir la ideología adecuada para hacer pasar como algo intrínsecamente beneficioso la compra de patentes.

Frente a esta situación los elementos críticos virtualmente contenidos en un complejo cultural autóctono no dejan de ser molestos para el Estado y para los empresarios. El examen crítico de las condiciones en que se produce la recepción tecnológica tiende a desvirtuar sus bondades, aceptadas irracionalmente. A este resultado confluyen también las observaciones de científicos no comprometidos con el "aparato productivo" y cuyo saber está enraizado en un examen detenido de las condiciones propias del hombre - no se puede leer...- Biólogos, antropólogos, sociólogos, urbanistas - no se puede leer... son una o dos frases...- no solo por cuanto significa la ruptura violenta e irreparable de patrones culturales, sino por cuanto deteriora, a un ritmo acelerado, condiciones ambientales y un equilibrio penosamente preestablecido.

Las llamadas ciencias básicas - lo mismo que las ciencias humanas - no solo pueden valorarse en la función que se les asigna como una información indispensable a nivel de estudios generales, sino por cuanto frente a la agresión tecnológica y a la ideología que la acompaña, significan la única posibilidad de evaluar críticamente los verdaderos aportes de la técnica y de las ideas.

\section{La defensa de las humanidades}

Frente a la agresión tecnológica y a los mitos ideológicos que la acompañan, nos encontramos en una situación en la que una noción abstracta e intemporal de "cultura" no posee virtualidad alguna. Peor todavía si se trata de un "humanismo" cómplice de esta agresión, el cual suele hablar de "valores universales" o de una "naturaleza humana invariable". Es claro que esta actitud universalista no hace otra cosa que propiciar la pérdida de los propios contornos culturales. 
La defensa de las "humanidades" como patrimonio abstracto, cuya guarda está confiada a unos pocos seres de excepción, no pasa de ser una de esas beaterías inofensivas que se mantienen con la sonrisa paternal y tolerante del sistema. De hecho, el sistema premia finalmente la beatería con alguna distinción académica o con alguna necrología reconfortante y justiciera.

En el interior de la universidad colombiana todo el mundo se mantiene demasiado ocupado como para pensar en impugnar la relevancia de las humanidades. Y en las facultades o departamentos que se ocupan de tales campos del saber, sus miembros están demasiado enquistados en una rutina, como para ocuparse ellos mismos en averiguar su propia relevancia en el contexto de la universidad. Así, la "cuestión de las humanidades" se ha delegado en instancias administrativas que acuden a índices de rentabilidad para decidir sin apelación sobre la inutilidad de un campo de saber. La preocupación de tales instancias, que son una prolongación del brazo del Estado, de los directorios políticos y de los grupos económicos de presión, no consiste precisamente, como en el siglo XIX y en las primeras décadas del actual, en repensar de manera abstracta la necesidad de un equilibrio entre los muchos interrogantes que pueden formularse acerca de la realidad, sino en responder con prontitud a las demandas de la empresa privada o a las exigencias de recortes fiscales por parte del Estado.

Hay que reconocer en honor a la verdad, que a las "humanidades" simplemente se les deja perecer por inanición. En el caso de las ciencias humanas la muerte ha sobrevivido de manera más violenta. No es casual que este rechazo de las ciencias de las humanas se presente con mayor fuerza en regímenes como los de Chile o Brasil. En nuestro país la persecución no ha alcanzado a la clerecía humanista y sólo se aplica allí en donde la argumentación intelectual llega a tocar las mitologías en las que se apoya el sistema.

Para aclarar este fenómeno es necesario volver un poco sobre los contenidos de la cultura y lo que designamos académicamente como "humanidades" y "ciencias humanas". La formación humanística persigue simplemente perpetuar el tipo humano que empezó a empollar en el siglo XVI y que iba a sustituir, en el ordenamiento social, a las viejas aristocracias que se extinguían con el sistema feudal. En Colombia, en donde sólo existe un remedo de las burguesías de los países capitalistas, este tipo humano es apenas marginal y un poco excéntrico. El remedo de cultura resulta demasiado evidente en un medio todavía provinciano y por eso no es raro que este tipo de educación se vea sustituido por preceptos mucho más pragmáticos, que se adaptan mejor a las funciones de una clase dominante.

Por el contrario, algunas concepciones dentro de las ciencias humanas no están uncidas a esta servidumbre ideológica y por eso poseen un potencial crítico que debería ser patrimonio de la universidad. En ausencia de una cultura codificada o analizada a nivel intelectual, la tarea de la universidad debe orientarse a rescatar el patrimonio y 
a universalizarlo. No en función de los intereses de una clase sino del grupo humano más basto que constituye nuestra formación social entera. Por eso no se trata, en modo alguno, de una tarea de anticuarios, sino de un trabajo que se refiere a elementos vivos y orgánicos.

La cultura, concebida como esta expresión de un modo de vida social entero, puede ser formalizada a un nivel intelectual mediante instrumentos conceptuales idóneos, proporcionados por el conjunto de las ciencias humanas. Aunque el Estado suele pensar su propia función en el campo de la cultura como una ocasión para establecer oficinas de propaganda o, peor, como el medio de distraer a la opinión pública de problemas fundamentales, todavía puede llegarse a un acuerdo en el interior de la universidad para retornar esta función en su verdadero sentido. 